\title{
Myśląc transformacje: przestrzenie uwspólniania podejścia epistemologicznego
}

\begin{abstract}
Abstrakt
Tekst, poprzez przedstawienie głównych linii wieloletniej współpracy profesora Jeana-Marie Barbiera z Uniwersytetem Łódzkim, Katedrą Pedagogiki Społecznej, a w wymiarze osobowym z profesor Ewą Marynowicz-Hetką, ukazuje proces dochodzenia do uwspólniania podejścia epistemologicznego, na przykładzie kategorii: „Myśląc transformacje”.

Kolejno omawiane są znaczące zdarzenia sprzyjające: rozpoznaniu wspólnych obszarów myślenia; poznawaniu koncepcji działania Jean-Marie Barbiera i jej interpretacji społeczno-pedagogicznej; wniknięciu w koncept transwersalnej analizy aktywności i jego zintegrowaniu z dyskursem społeczno-pedagogicznym oraz konstruowaniu projektu badawczego: „myśląc transformacje”.
\end{abstract}

Słowa kluczowe: uwspólnianie podejścia epistemologicznego, myśląc transformacje, transwersalna analiza aktywności.

\section{Thinking Transformations: Spaces for Sharing the Epistemological Approach}

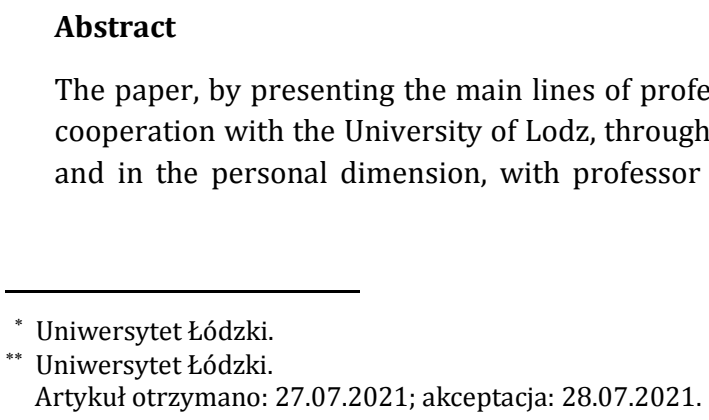

* Uniwersytet Łódzki.

** Uniwersytet Łódzki.

Artykuł otrzymano: 27.07.2021; akceptacja: 28.07.2021.

The paper, by presenting the main lines of professor Jean-Marie Barbier's long-term cooperation with the University of Lodz, through the Department of Social Pedagogy, and in the personal dimension, with professor Ewa Marynowicz-Hetka, shows the 
process of reaching the common epistemological approach, using the example of the category "Thinking transformations".

Significant events that contribute to: recognition of common areas of thought; knowing about Jean-Marie Barbier's concept of action and its socio-pedagogical interpretation; penetrating the concept of a transversal analysis of activity and its integration with the socio-pedagogical discourse and constructing a research project: 'thinking transformations', are discussed sequentially.

Keywords: sharing the epistemological approach, thinking transformations, transversal analysis of activity.

\section{Punkt wyjścia}

Rozwijane w tym numerze tematycznym podejście epistemologiczne do analizy aktywności w polu praktyki, określane terminem: „myśląc transformacje”, wyraża aktualny poziom porozumienia intelektualnego badaczy, osiągnięty dzięki współpracy naukowej datującej się, w kontakcie osobowym ${ }^{1}$, od końca lat dziewięćdziesiątych XX w., a w kontakcie pośrednim (lektury)² od początku tych lat. Współpraca naukowa pomiędzy Jean-Marie Barbierem ${ }^{3}$ a Ewą Marynowicz-Hetką ${ }^{4}$ długa historia wzajemnych kontaktów i wydarzeń, doprowadziła w efekcie do uwspólnienia poglądów epistemologicznych i ich upowszechnienia $\mathrm{w}$ zespołach badawczych: francuskim i polskim.

W tym krótkim tekście pragniemy zasygnalizować znaczące wydarzenia, które sprzyjały wymianie intelektualnej. Zostały one poddane dyskusji między autorkami tekstu i jego treść oddaje te stanowiska. Z uwagi na zasięg temporalny tej współpracy przygotowanie krótkiego tekstu stało się dla nas sporym wyzwaniem. Ważną w nim funkcję, umożliwiającą wyjaśnienie i pogłębienie informacji o zdarzeniach, spełniają odniesienia w przypisach i wskazówki bibliograficzne.

\footnotetext{
1 Maj 1998, konferencja we francuskim Ministerstwie Pracy Socjalnej poświęcona kształceniu pracowników socjalnych we Francji, do udziału w której zostali zaproszeni: Jean-Marie Barbier i Ewa Marynowicz-Hetka jako eksperci zewnętrzni projektu badawczego poświęconego przesłankom epistemologicznym pracy socjalnej, prowadzonego przez Ecole Supérieure du Travail Social (ETSUP; Wyższa Szkoła Pracy Socjalnej) w Paryżu.

2 Por. Barbier (1991). Chodzi tu o publikację Barbiera poświęconą opracowaniu projektu, której wydanie we Francji zbiegło się z intensywnymi pracami w Polsce, związanymi z modyfikacją systemu kształcenia pracowników socjalnych, w którym projektowanie socjalne stanowiło główny trzon programu kształcenia (por. Marynowicz-Hetka, Piekarski 1996).

3 Profesor Jean-Marie Barbier, założyciel i wieloletni dyrektor Centre de Recherche en Formation des Adults [Cenrum badań nad kształceniem dorosłych] w Conservatoire National des Arts et Métiers (CNAM), w Paryżu. Także inicjator powstania w 2013 r. Katedry UNESCO: Formation et Pratiques professionnelles w CNAM, a następnie Katedry UNESCO w Institut Catholique de Paris (ICP). Przybliżający w swych pracach konceptualizację świata praktyki/ów/profesjonalistów i wyrażający go w języku metateoretycznym.

${ }_{4}$ Profesor Ewa Marynowicz-Hetka, wieloletni kierownik Katedry Pedagogiki Społecznej Uniwersytetu Łódzkiego, współpracująca z licznymi placówkami badawczymi we Francji, w tym w Paryżu z ETSUP, CNAM, ICP.
} 
Omawiana współpraca naukowa wpisywała się w kontekst historyczny, społeczny, indywidualny i instytucjonalny, była w trakcie stawania się: od widocznego jednostronnego przepływu koncepcji, sposobu postrzegania, języka5, do poczucia wymiany intelektualnej, które pozwala nam myśleć w kategoriach kolektywu myślowego (Fleck 1986) czy uwspólnionego (Dewey 1968) podejścia epistemologicznego, widocznego w tekstach składających się na ten numer tematyczny.

Konstruowanie uwspólnionego podejścia epistemologicznego było długim procesem mentalnym, zapoczątkowanym poszukiwaniem inspiracji dla postrzegania działania w polu praktyki, a przede wszystkim zasobów konceptów je określających. Upowszechnienie dokonań badawczych napotkanych w pracach Barbiera dotyczyło wielu aspektów. Szczególnie owocne były prace nad narzędziami analizy działania i jego pojmowania oraz wyrażania w precyzyjnie budowanym słownictwie. Apogeum tych prac znalazło się w leksykonie (Barbier 2016b, 2017) analizy aktywności, który poprzez konceptualizacje zwyczajowych pojęć obecnych w polu praktyki wskazał na podstawy epistemologiczne oraz kulturę badania proponującą „odkrycie aktywności” (éntrée à l'activité) (por. Barbier, Durand 2003; Barbier 2016b: 133-136). Dyskurs ten upowszechniany dzięki tłumaczeniom na język polski (Barbier 2006; 2015; 2016a; 2016b; 2020), określony jako transwersalna koncepcja analizy działania (Marynowicz-Hetka 2016), został ufundowany na transwersalnym i holistycznym ujmowaniu aktywności jako przedmiotu namysłu/badania, w odniesieniu do aktywności usytuowanych. Barbierowska myśl transwersalna, płynąca do polskiego środowiska badaczy społecznych, niosła ze sobą ideę przekraczania potocznego, zwyczajowego horyzontu myślenia o aktywności usytuowanej, pobudzania do analizy pozwalającej odnajdywać dotąd nieoczywiste związki w procesie wnioskowania o jej sensie i znaczeniu, jednocześnie pozbawione aspektów życzeniowych i oczekiwanych.

Te przesłanki koncepcji określanej też „antropologią aktywności”, skierowane do polskich odbiorców ${ }^{6}, \mathrm{w}$ tym do polskiego środowiska pedagogów społecznych, znalazły odzwierciedlenie w konstytuowaniu podejścia do analizy działania/aktywności w polu praktyki.

\section{Uwspólnianie podejścia epistemologicznego, z kalendarium wydarzeń $w$ tle}

Linearne przedstawienie wszystkich wydarzeń stanowiących przestrzeń uwspólniania podejścia epistemologicznego do analizy działania w polu praktyki mogłoby być bardzo interesujące, ale nie spełniałoby warunku tekstu ukazującego prze-

\footnotetext{
5 Por. m.in. Kafar, Marynowicz-Hetka 2021, w tym tomie.

6 Szczególnie należy przywołać prace Lecha Witkowskiego (por. m.in. 2009, 2018), który był recenzentem pierwszej książki Barbiera, opublikowanej w języku polskim (Barbier 2006), i od tego czasu towarzyszył naszemu środowisku w inicjatywach podejmowanych we współpracy z profesorem Barbierem.
} 
strzenie tej współpracy, która doprowadziła do przygotowania niniejszego numeru tematycznego. Z tego powodu wskazujemy na wybrane znaczące wydarzenia, wpisujące się $\mathrm{w}$ owe przestrzenie $\mathrm{w}$ takim porządku:

- rozpoznanie wspólnych obszarów myślenia obejmujące pierwsze kontakty wirtualne i osobowe oraz pierwsze formy współpracy w latach 1991-2001. Ich zwieńczeniem był kongres European Association of Social Work (EASSW) w Łodzi wraz ze znaczącym udziałem Jean-Marie Barbiera;

- od 2002 r. wpisywanie koncepcji aktywności Barbiera w dyskurs działania społecznego i jej interpretacja społeczno-pedagogiczna, zwieńczona publikacją jego książki w języku polskim (Barbier 2006), oraz obecnością tej koncepcji w podręczniku z pedagogiki społecznej (Marynowicz-Hetka 2006);

- intensywna wymiana intelektualna, trwająca przynajmniej dziesięć lat (20072017), wymagająca przekraczania granic kulturowych i językowych oraz społeczno-pedagogiczna interpretacja transwersalnej analizy aktywności, zwieńczona przekładem na język polski Leksykonu analizy aktywności... (Barbier 2016) i rozprawą doktorską Izabeli Kamińskiej-Jatczak;

- ukierunkowanie współpracy na problematykę: „myśląc transformacje”, która zajmowała zespoły badawcze przez okres ostatnich trzech lat (2018-2021) i znalazła sfinalizowanie w tymże numerze tematycznym.

\section{Rozpoznanie wspólnych obszarów myślenia}

W procesie rozpoznawania wspólnych obszarów myślenia można wyodrębnić kilka faz. Pierwsza z nich (1991-1997) rozwijała się w przestrzeni mentalnej poprzez obcowanie z twórczością Jean-Marie Barbiera (1991) i przede wszystkim przez recepcję książek i artykułów, zwłaszcza książkę pt. Élaboration de projet d'action et planification [Opracowanie projektu działania i planowanie], która w tym czasie była cennym źródłem wiedzy, w związku z powszechnie używaną kategorią projektowania, także wprowadzoną do nowego programu kształcenia pracowników socjalnych w policealnych szkołach służb społecznych w Polsce.

Druga z faz (1998-1999) poznawania obszarów myślenia obejmowała problematykę kształcenia pracowników socjalnych na poziomie wyższym i włączała się w żywe, w tym czasie w Europie i w Polsce, tendencje do nadawania kształceniu wymiaru akademickiego. Przejawem tego była współpraca w roli zewnętrznych ekspertów w projekcie badawczym Problèmes épistémologiques de la recherche en travail social/Epistemological Issues in Social Work Research [Problemy epistemologiczne badań w pracy socjalnej], pilotowanym przez École Supérieure de Travail Social (ETSUP) w Paryżu [Wyższą Szkołę Pracy Socjalnej].

Trzecia z faz (2000-2001) rozpoznawania obszarów myślenia obejmuje przejawy współpracy bieżącej, m.in. w roku 2000 współudział Uniwersytetu Łódzkiego, a ściśle Katedry Pedagogiki Społecznej UŁ, w pracach koncepcyjnych powołania 
w CNAM, z inicjatywy profesora Barbiera, konsorcjum 28 uczelni europejskich, kanadyjskich i południowo-amerykańskich pod nazwą Institut de Recherche sur la Formation des adultes et les Activités professionnelles (IERFA) [Instytut badań nad kształceniem dorosłych i aktywnościami profesjonalnymi]. Było to konsorcjum uczelni, w ramach którego realizowano uniwersytet doktorski, biennale edukacji i praktyk profesjonalnych, oraz podejmowane były projekty badawcze. Celem tego organizmu było tworzenie przestrzeni wymiany intelektualnej i upowszechnianie (udostępnianie) rezultatów badawczych w międzynarodowej społeczności badaczy.

Ważnym elementem konstruowania przestrzeni rozpoznawania wspólnych obszarów myślenia były pierwsze bilateralne wizyty studyjne: profesora Barbiera w Katedrze Pedagogiki Społecznej U乇 i profesor Marynowicz-Hetki w Centre de Recherche sur la Formation, w Conservatoire National des Arts et Métiers w Paryżu, poświęcone dyskusjom naukowym i wykładom dla studentów obu uczelni. Ta forma współpracy, kontynuowana w następnych latach, spełniała funkcję poznawczą, służącą rozpoznawaniu wspólnych obszarów myślenia. Szczególnym jej wyrazem było zaproszenie profesora Barbiera przez EASSW i Komitet Polski w 2001 r. do przedstawienia jednego z głównych wykładów na kongresie EASSW ${ }^{7}$ w Łodzi, dotyczącego teoretycznych podejść do kształcenia w obszarze pracy socjalnej ${ }^{8}$.

\section{Koncepcja działania Jean-Marie Barbiera $\mathrm{i}$ jej interpretacja społeczno-pedagogiczna}

Początek współpracy mentalnej, wyrażającej się uwspólnianiem myślenia na temat działania/aktywności, należałoby łączyć z pobytem studyjnym (2002, wrzesień/ październik) Ewy Marynowicz-Hetki w CNAM w ramach formuły visiting professor i pierwszymi pracami koncepcyjnymi oraz translacyjnymi nad projektowanym wyborem tekstów Barbiera, które opublikowane zostały w książce (Barbier 2006), w serii Biblioteka Pracownika Socjalnego. Przygotowanie tej książki stało się przestrzenią rzeczową do dyskusji nad zestawem pojęć kluczowych, obecnych w twórczości tego autora, pozwoliło na jej zrozumienie i pojęcie znaczenia dla pogłębiania dyskursu społeczno-pedagogicznego. Było to o tyle ważne, że w tym czasie, po 40 latach, powstawał nowy podręcznik pedagogiki społecznej (Marynowicz-Hetka 2006), w którym widoczne są inspiracje tą twórczością oraz próba zinterioryzowania idei pedagogiki społecznej z koncepcją działania/aktywności Barbiera.

\footnotetext{
7 Chodzi o kongres European Association of Social Work na temat: Theoretical Approaches in Social Work Education/Approches théoriques dans l'éducation du travail social, który odbył się w Łodzi w dniach 6-9 czerwca $2001 \mathrm{r}$.

8 Wykład odwoływał się do konceptualizacji pojęć związanych z kształceniem profesjonalnym: Savoir. Capacités. Compétences [Wiedza, możliwości/potencjały, kompetencje] interesujących środowisko nauczycieli, badaczy i praktyków pracy socjalnej/społecznej. Był zwiastunem idei „antropologii aktywności” w późniejszych pracach badawczych profesora Barbiera (por. Labonté-Roset, Marynowicz-Hetka, Szmagalski 2002).
} 
W integrowaniu myślenia na temat działania znaczące były dwa wydarzenia edycyjne: równoległe opublikowanie jesienią 2006 r. pierwszego tomu podręcznika $\mathrm{z}$ pedagogiki społecznej oraz pierwszego wydania w języku polskim tekstów Barbiera. Temu celowi sprzyjały także inne inicjatywy stanowienia przestrzeni współmyślenia, m.in. współorganizowanie w CNAM seminarium pt: Valeurs et les activités professionnelles. Le cas du travail social [Wartości i działania profesjonalne. Przykład pracy socjalnej]. Seminarium było zorientowane na środowisko badaczy pola pracy socjalnej i kształcenia, odnosiło się do kwestii miejsca wartości w polu działania społecznego. Rezultaty debaty zostały opublikowane w czasopiśmie „Vie Sociale" i stały się punktem wyjścia do dalszej pracy badawczej nad wymiarem aksjologicznym działania/aktywności w polu praktyki.

\section{Koncept transwersalnej analizy aktywności Barbiera i jego zintegrowanie z dyskursem społeczno-pedagogicznym}

Przestrzeń integrowania transwersalnej analizy aktywności z dyskursem społeczno-pedagogicznym była ukierunkowana na przekład pojęć tej koncepcji na język polski i udostępnienie ich polskiej publiczności badaczy społecznych. Ważnym wydarzeniem (październik 2016) była dyskusja panelowa wokół problematyki zawartej w książce J.-M. Barbiera (2016) Leksykon analizy aktywności. Konceptualizacje zwyczajowych pojęć, zorganizowana w ramach 70. rocznicy powstania Uniwersytetu Łódzkiego, jak i Katedry Pedagogiki Społecznej UŁ (Kamińska-Jatczak, Skoczylas-Namielska 2016). Kontakt polskich badaczy i studentów/doktorantów ${ }^{9}$ z myślą transwersalną był pogłębiany na seminariach warsztatowych, wystąpieniach i wykładach z udziałem profesora Barbiera ${ }^{10}$, co skutkowało włączaniem jej

\footnotetext{
${ }^{9}$ Odnotować należy zwłaszcza:

- wystąpienie plenarne Jean-Marie Barbiera na temat: Entrer par l'activité: aspects épistémologiques, théoriques, méthodologiques, sociaux des recherches liant enjeux scientifiques, enjeux de formation/ professionnalisation et enjeux d'optimisation de l'action [Odkrycie aktywności: aspekty epistemologiczne, teoretyczne, metodologiczne, społeczne badań wiążących wymiary naukowe z kształceniowymi/profesjonalizacyjnymi i optymalizacyjnymi], na konferencji (29-30.09, 2016) Participatory Social Work: Approaches, Barriers, Critique, współorganizowanej przez Katedrę Pedagogiki Społecznej UŁ z European Research Institute for Social Work (ERIS);

- pobyt studyjny profesora Barbiera w Łodzi w listopadzie 2017 r.: wykład dla doktorantów łódzkich uczelni: Anthropologie partagée des activités [Podzielana antropologia aktywności]. Wykład odbył się w związku z otrzymaniem nagrody za prace badawcze z pedagogiki społecznej im. Profesor Ireny Lepalczyk, przyznanej przez Łódzkie Towarzystwo Naukowe;

- uczestnictwo w seminarium warsztatowym, organizowanym przez Katedrę Pedagogiki Społecznej UŁ, pod tytułem Wokół transwersalnej koncepcji analizy aktywności.

${ }^{10}$ Szczególnie należałoby wymienić: pobyty studyjne profesora Barbiera w Katedrze Pedagogiki Społecznej UŁ, wykłady dla studentów, dyskusje, seminarium poświęcone książce Działanie $w$ kształceniu i pracy socjalnej. Analiza podejść (Barbier 2006) czy wystąpienie Marynowicz-Hetki w ramach Première Université doctorale d'automne [Pierwszego, jesiennego Uniwersytetu doktorskiego] w listopadzie 2010, zatytułowane: Champs de recherches, champs de pratiques: tendances méthodologiques et épistémologiques de la recherche [Pola badań, pola praktyk: tendencje metodologiczne i epistemologiczne badań].
} 
w badania prowadzone w Katedrze. Koncepcja transwersalnej analizy aktywności stała się ramą teoretyczną w rozprawie doktorskiej Izabeli Kamińskiej-Jatczak (2017), w której stanowiła główne odniesienie teoretyczne, co było przedmiotem dyskusji z profesorem Barbierem podczas obrony tej pracy.

Przestrzenią wymiany intelektualnej były też recenzje rozpraw doktorskich, przygotowanych pod kierunkiem profesora Barbiera, a także kolejne (lipiec 2013; 2015) Biennale Internationale de l'Education et des pratiques professionnelles i uniwersytety doktorskie, organizowane w CNAM ${ }^{11}$. Ważnym zapleczem dla międzynarodowej współpracy była obecność Katedry Pedagogiki Społecznej UŁ w tworzeniu i rozbudowywaniu inicjatyw instytucjonalnych w CNAM ${ }^{12}$.

Kolejnym ogniwem integrowania myślenia społeczno-pedagogicznego z koncepcją transwersalnej analizy aktywności były wspólne prace badawcze nad kulturą edukacyjną i kulturą społeczną, uwieńczone współredagowanym numerem czasopisma „Nauki o Wychowaniu. Studia Interdyscyplinarne” [NOWIS 2016/2(3)].

Integrowanie koncepcji transwersalnej analizy aktywności z perspektywą społeczno-pedagogiczną w polu praktyki znalazło najsilniejszy wymiar w monografii Marynowicz-Hetki (2019). Ramy epistemologiczne tego procesu są omawiane przez tę autorkę w artykule publikowanym w niniejszym numerze.

\section{Projekt badawczy: myśląc transformacje}

Tytułowy projekt był realizowany od 2015 r. w ramach pola badawczego obejmującego Laboratorium Excelence HASTEX, Histoire et anthropologie des Savoirs, des Techniques et des Croyances [Historia i antropologia wiedzy, techniki i przekonań/wierzeń]. Międzynarodowy zespół, pod kierunkiem profesora Barbiera (CNAM) oraz Marka Duranda (Uniwersytet w Genewie), prowadził prace badawcze na temat: Représentations de transformations opérées par l'activité humaine dans le champ des arts et métiers [Reprezentacje transformacji wyrażane poprzez aktywność człowieka w polach sztuk i zawodów]. W trakcie dyskusji, na systematycznie organizowanych seminariach badawczych, podejmujących zagadnienia reprezentacji transformacji, pojawiła się kategoria Penser les transformations [Myśląc transformacje]. Ta kategoria została sformułowana przez profesora Barbiera (2018) w jednym z tekstów stanowiących ramy teoretyczne projektu. Rezultaty badań13

\footnotetext{
${ }^{11}$ Bliżej na ten temat: Marynowicz-Hetka (2015).

12 M.in. uczestnictwo w grupie inicjatywnej Katedry UNESCO (2013) i wspieranie inicjatywy (2009) współtworzenia sieci naukowej Groupement d’Intérêt Scientifique (GIS) w ramach współpracy z Institut Européen de Recherche sur la Formation et l'Analyse de l'activité (IERFA).

${ }^{13}$ Ewa Marynowicz-Hetka (2018) podjęła zagadnienie kluczowe dla myślenia o transformacjach w kategoriach społeczno-pedagogicznych, analizując transformacje bezszelestne, zachodzące w polu praktyki pracy socjalnej/społecznej, odwołując się do rezultatów badań zawartych w dwu rozprawach doktorskich przygotowywanych pod jej kierunkiem: Izabeli Kamińskiej-Jatczak (2017) i Moniki Wojtczak (2016).
} 
zostały opublikowane w pracy zespołowej (Barbier, Durand 2018) pt. Représenter/ Transformer: Débats en analyse des activités, omawianej w tym numerze przez Lecha Witkowskiego.

Dzięki temu projektowi przestrzeń współmyślenia o transformacjach przeszła w fazę międzynarodowej wymiany intelektualnej i ukierunkowała dalsze formy współpracy, co zaowocowało sympozjum naukowym w 2019 r. ${ }^{14}$ poświęconym tej problematyce. W ramach sympozjum poszukiwano narzędzi intelektualnych (konceptów) pozwalających na uchwycenie złożoności procesów transformacji zachodzących nieustannie w życiu człowieka (por. Kamińska-Jatczak 2019). Namysł był kontynuowany, dzięki czemu zawiązała się współpraca zespołu autorów polskich i francuskich nad aktualnym numerem: Myśląc transformacje.

\section{Zamiast zakończenia}

Omawiana współpraca naukowa, owocująca transwersalnym, uwspólnionym podejściem do aktywności, trwa nadal, choć instytucjonalnie związana jest z innymi organizmami: Katedrą UNESCO ${ }^{15}$ : Formation professionnelle, construction personnelle, transformations sociales [Kształcenie profesjonalne, konstruowanie osoby, transformacje społeczne], istniejącą w Institut Catholique w Paryżu i Łódzkim Towarzystwem Naukowym, w którym projektowane było na 1 czerwca 2020 r. (udaremnione przez pandemię Covid) seminarium kontynuujące problematykę „myśląc transformacje”. Jego organizacja pozostaje nadal w naszych planach i, co więcej, będzie mogła być poszerzona o dyskusję na temat tego numeru tematycznego oraz zawartych w nim treści. Wstępna zapowiedź16 jego publikacji w środowisku międzynarodowym będzie możliwa już wkrótce (22-25 września 2021 r.), na kolejnym jedenastym Międzynarodowym Biennale Edukacji, Kształcenia i Praktyk Profesjonalnych [11 Biennale Internationale de l'Éducation, de la Formation et des Pratiques professionnelles], któremu przewodniczy profesor Jean-Marie Barbier. Wykład inauguracyjny wygłosi François Jullien (2017), autor ważny dla naszej społeczności badaczy z uwagi na jego prace poświęcone transformacjom niewidocznym/bezszelestnym. Trwanie idei i nowe otwarcie tej współpracy są widocznym wyrazem podzielanego i żywego zainteresowania rozwijaniem paradygmatu odkrywania aktywności oraz wynikającej z niego kultury badania.

\footnotetext{
${ }^{14}$ Sympozjum było naukowym wydarzeniem towarzyszącym uroczystości przyznania profesorowi Barbierowi przez Senat Uniwersytetu Łódzkiego Medalu Universitatis Lodziensis Amico/Przyjaciel Uniwersytetu Łódzkiego.

150 jej aktywności i aktualnym projekcie badawczym: „Se préparer à l’action” [Przygotowanie się do działania] piszą w tym numerze Jean-Marie Barbier i Martine Dutoit.

${ }^{16}$ Dobrą sposobnością będzie moderowanie warsztatu pt: Faire et se faire entre cultures et identité [Czynić i się czynić/stawać między kulturami i tożsamością], które organizatorzy powierzyli Ewie Marynowicz-Hetce.
} 


\section{Bibliografia}

Barbier J.-M. (1991) Élaboration de projet d'action et planification, Paris, Presses Universitaire de France.

Barbier J.-M. (2006) Działanie w kształceniu i pracy socjalnej. Analiza podejść, tłum. G. Karbowska, konsultacja naukowa E. Marynowicz-Hetka, Kraków, Wydawnictwo Naukowe „Śląsk”, seria Biblioteka Pracownika Socjalnego.

Barbier J.-M. (2015) Nowe wyzwania dla badań w naukach o wychowaniu: perspektywa działania/aktywności, tłum. G. Karbowska, konsultacja naukowa E. Marynowicz-Hetka, „Nauki o Wychowaniu. Studia Interdyscyplinarne”, nr 1 (1), s. 60-72.

Barbier J.-M. (2016a) Kultury działania i podzielane sposoby organizacji konstrukcji sensu, tłum. G. Karbowska, konsultacja naukowa E. Marynowicz-Hetka, „Nauki o Wychowaniu. Studia Interdyscyplinarne”, nr 2 (3), s. 14-46, https://doi.org/10.18778/ 2450-4491.03.02

Barbier J.-M. (2016b) Leksykon analizy aktywności. Konceptualizacje zwyczajowych pojęć, tłum. i oprac. E. Marynowicz-Hetka, Łódź, Wydawnictwo Uniwersytetu Łódzkiego.

Barbier J.-M. (2017) Vocabulaire d'analyse des activités. Penser les conceptualisations ordinaires, Paris, Presses Universitaires de France.

Barbier J.-M. (2018) Penser en termes de transformation w: Représenter/transformer. Débats en analyse des activités, J.-M. Barbier, M. Durand (red.), we współpracy C. Cohen, M.-L. Vitali, Paris, L'Harmattan, s. 11-23.

Barbier J.-M. (2020) Konstruowanie aktywności i podmiotu w aktywności - wzajemne powiq̨zania, tłum. G. Karbowska, konsultacja naukowa L. Witkowski w: Pedagogika społeczna. Spotkania, trwanie i zmienność, pogranicza, A. Walczak, L. Telka, M. Granosik (red.), Łódź, Wydawnictwo Uniwersytetu Łódzkiego, seria Stała Konferencja Pedagogiki Społecznej pod patronatem Komitetu Nauk Pedagogicznych PAN, t. 10, s. 223-230.

Barbier J.-M., Durand M. (2003) L'activité : un objet intégrateur pour les sciences sociales?, «Recherche \& Formation », $\mathrm{n}^{\circ} 42$, J.-M. Barbier, M. Durand (dir.), L'analyse de l'activité. Approches situées, s. 99-117, https://doi.org/10.3406/refor.2003.1831

Barbier J.-M., Durand M. (red.) (2018) Représenter/transformer. Débats en analyse des activités, we współpracy C. Cohen, M.-L. Vitali, Paris, L'Harmattan.

Dewey J. (1968) Expérience et éducation, tłum. na j. francuski M. A. Carroi, Paris, Librairie Armand Colin. 
Fleck L. (1986) Powstanie i rozwój faktu naukowego. Wprowadzenie do nauki o stylu myślowym i kolektywie myślowym, tłum. M. Tuszkiewicz, wstęp Z. Cackowski, Lublin, Wydawnictwo Lubelskie.

Jullien F. (2017) Une seconde vie. Comment véritablement exister, Paris, Grasset.

Kafar M., Marynowicz-Hetka E. (2021) O przepływach intelektualnych: spotkania dialogowe, „Nauki o Wychowaniu. Studia Interdyscyplinarne”, nr 2 (13), w tym tomie.

Kamińska-Jatczak I. (2019) Myślq̨c o transformacjach: Sympozjum naukowe (Łódź, 23.05.2019), „Nauki o Wychowaniu. Studia Interdyscyplinarne”, nr 1 (8), s. 312-323, https://doi.org/10.18778/2450-4491.08.23

Kamińska-Jatczak I. (2021) Aktywność asystentów rodziny. Analiza narracji w ujęciu transwersalnym, Łódź, Wydawnictwo Uniwersytetu Łódzkiego.

Kamińska-Jatczak I., Skoczylas-Namielska E. (2016) Pedagogika społeczna w Uniwersytecie Łódzkim: przeszłość - teraźniejszość - przyszłość: kulminacja obchodów 70-lecia Katedry Pedagogiki Społecznej UŁ, „Nauki o Wychowaniu. Studia Interdyscyplinarne”, nr 2 (3), s. 215-232, https://doi.org/10.18778/2450-4491.03.13

Labonté-Roset Ch., Marynowicz-Hetka E., Szmagalski J. (red.) (2002) Social Work Education and Practice in Today's Europe. Challenges and the Diversity of Responses/ La Formation et l'action dans le travail social pour l'Europe d'aujourd hui. Les défis et la diversité des solutions, Katowice, Wydawnictwo Naukowe „Śląsk”, seria Biblioteka Pracownika Socjalnego.

Marynowicz-Hetka (2006) Pedagogika społeczna. Podręcznik akademicki. Wykład, t. 1, Warszawa, Wydawnictwo Naukowe PWN.

Marynowicz-Hetka E. (2015) Katedra UNESCO: Kształcenie i Praktyki Profesjonalne (Chaire UNESCO: «Formation et des Pratiques professionnelles») - zakres aktywności, „Nauki o Wychowaniu. Studia Interdyscyplinarne”, nr 1, s. 192-197.

Marynowicz-Hetka E. (2016) Posłowie. Konceptualizacje zwyczajowych ram myślenia o aktywności - na marginesie pracy nad tekstem w: J.-M. Barbier, Leksykon analizy aktywności. Konceptualizacje zwyczajowych pojęć, tłum. i oprac. E. Marynowicz-Hetka, Łódź, Wydawnictwo Uniwersytetu Łódzkiego, s. 271-289.

Marynowicz-Hetka E. (2018) Transformations invisibles/silencieuses et champ du travail social w: Représenter/transformer. Débats en analyse des activités, J.-M. Barbier, M. Durand (red.), we współpracy C. Cohen, M.-L. Vitali, Paris, L’Harmattan, s. 183-202.

Marynowicz-Hetka E. (2019) Pedagogika społeczna. Pojmowanie aktywności w polu praktyki, Łódź, Wydawnictwo Uniwersytetu Łódzkiego. 
Marynowicz-Hetka E., Piekarski J. (red.) (1996) Wokół problemów działania społecznego. Wybór tekstów i przykłady projektów działania, Warszawa, Interart, seria Biblioteka Pracownika Socjalnego.

„Vie Sociale” 2003, numer tematyczny: Entre normes et valeurs : le cas du travail social, $\mathrm{nr} 4$.

Witkowski L. (2009) W stronę kultury profesjonalizacji. Koncepcja Jean-Marie Barbiera działania w pedagogice społecznej(esej recenzyjny nie tylko na rzecz pracy socjalnej w: L. Witkowski, Ku integralności edukacji i humanistyki. Postulaty, postacie, pojęcia, próby. Odpowiedź na księgę jubileuszowq, Toruń, Wydawnictwo Adam Marszałek, s. 291-315.

Witkowski L. (2018) Humanistyka stosowana. Wirtuozeria, pasje, inicjacje. Profesje społeczne versus ekologia kultury, Kraków, Oficyna Wydawnicza „Impuls”.

\section{Źródła internetowe}

Kamińska-Jatczak I. (2017) Tożsamość profesjonalna w narracjach asystentów rodziny, niepublikowana praca doktorska, mpis, https://repozytorium.uni.lodz.pl/handle/ 11089/23030 [dostęp: 11.04.2021].

„Nauki o Wychowaniu. Studia Interdyscyplinarme” (2016), nr 2 (3), numer tematyczny: Kultury edukacyjne i kultury społeczne, E. Marynowicz-Hetka, J.-M. Barbier (red.), https://czasopismo.naukiowychowaniu.uni.lodz.pl/resources/html/articlesList?issu eId=10320 [dostęp: 27.07.2021].

Wojtczak M. (2016) Przestrzeń społeczna szkoły - rekonstrukcja z punktu widzenia podejść mediacyjnych, niepublikowana praca doktorska, mpis, https://dspace.uni .lodz.pl/bitstream/handle/11089/20080/przestrzen_spoleczna_szkoly_MW.pdf?seq uence=1\&isAllowed=y [dostęp: 26.07 .2021 ].

\section{Thinking Transformations: Spaces for Sharing the Epistemological Approach}

\section{Summary}

The article is an example of the development of international cooperation, in which the mental activity of its partners shaped its essence. This cooperation has evolved from "mere" interest in creativity, to an epistemological understanding in relation to the analysis of action/activity in the field of practice.

The course of this process of sharing positions and their mutual enrichment is documented with references to significant events of this cooperation, carried out between Jean-Marie Barbier from the Conservatoire Nationale des Arts et Métiers in 
Paris and Ewa Marynowicz-Hetka from the University of Lodz, managing research teams that were gradually included in its course. The calendar of events is extensive. It begins in 1991, the date of the publication of a book by Barbier (1991), important for the community of social educators in Poland, dealing with the issue of design and planning. Further, the events that make up the gradual recognition of common areas of thinking, initiated by the real contact of partners at the end of the 1990s, are referred to.

Over the years, individual events have accumulated to create a new, significant scientific quality, such as translation of texts, publications in both languages, participation in the education of researchers and international projects. In the article, we discuss the features of this cooperation, requiring the crossing of cultural and linguistic boundaries and resulting in a socio-pedagogical interpretation of the main concepts of Barbier's work and their integration with the discourse of social pedagogy. The work on the tools for analysing action and its understanding and expression in precisely constructed vocabulary was particularly fruitful.

The discussed cooperation is fitted into the historical, social, individual and institutional context. Its process of becoming was from the visible one-sided flow of concepts, perceptions, and language, to a sense of intellectual exchange that allows us to think in terms of a mental collective (Fleck 1986), or a shared (Dewey 1968) epistemological approach to the category of "thinking transformations", visible in the texts that make up this thematic issue.

\section{Penser transformations : les espaces de partage de l'approche épistémologique}

\section{Résumé}

L'article est un exemple du développement d'une coopération internationale où l'activité mentale de ses partenaires a joué un rôle majeur. Cette coopération a évolué d'un «simple » intérêt pour les écrits à un accord épistémologique envers l'analyse de l'activité dans le champ de la pratique.

Le déroulement du processus de partage des positions et de l'enrichissement réciproque peut être documenté par les événements majeurs de cette coopération, réalisée entre Jean-Marie Barbier du Conservatoire Nationale des Arts et Métiers à Paris et Ewa Marynowicz-Hetka de l'Université de Łódź, dirigeants des équipes de recherche, celles-ci rejoignant successivement ce travail. Le calendrier des événements marquants de cette coopération est très riche. Il commence en 1991, l'année de la publication du livre très important pour le milieu des pédagogues sociaux en Pologne où J.-M. Barbier (1991) s'intéresse à la problématique d'élaboration et de planification d'un projet. Par la suite, nous citons des événements permettant à reconnaître nos champs de penser respectifs, inaugurés par le contact réel des partenaires à la fin des années 90 du XX siècle. Au cours des années, des événements ponctuels s'accumulent d'importante qualité scientifique, comme 
par exemple les traductions des textes, des publications dans les deux langues, la participation à la formation des chercheurs et aux projets de recherche internationaux.

Dans l'article, nous parlons des traits caractéristiques de cette coopération, qui nous a permis de franchir les frontières culturelles et langagières, ainsi que des concepts majeurs développés par J.-M. Barbier avec leur interprétation sociopédagogique, et leur intégration au discours de la pédagogie sociale. Il faudrait particulièrement souligner les travaux sur les outils d'analyse des activités et leur intelligibilité, ainsi que la clarté de l'expression grâce à une très grande précision du vocabulaire employé.

Cette coopération s'est bien inscrite au contexte historique, social, individuel et institutionnel. Le processus et son devenir a commencé par un flux visible des conceptions et des moyens de perception. L'échange intellectuel nous a permis de penser dans les catégories d'un collectif de pensée (Fleck 1986), ou une approche épistémologique partagée (Dewey 1968) dans la catégorie "penser les transformations» que l'on peut reconnaître dans les textes composant ce numéro thématique.

\section{Cytowanie}

Kamińska-Jatczak I., Marynowicz-Hetka E. (2021) Myśląc transformacje: przestrzenie uwspólniania podejścia epistemologicznego , „Nauki o Wychowaniu. Studia Interdyscyplinarne" 2(13), 340-352, https://doi.org/10.18778/2450-4491.13.20 